\title{
La punción seca sería efectiva en el tratamiento del dolor de cuello y hombro asociados a puntos gatillos miofasciales
}

Dry needling would be effective to treat patients with neck and shoulder pain associated with myofascial trigger points

Lin L, y col. Arch Phys Med Rehabil. 2015 May;96(5):944-55.

\section{Objetivos}

Evaluar la eficacia de la punción seca (PS) para tratar puntos gatillos miofasciales (PGM) asociados al dolor de cuello y hombro.

\section{Diseño}

Revisión sistemática y meta-análisis.

\section{Fuente de Datos}

Se realizaron búsquedas en las siguientes bases desde sus inicios y hasta enero del 2014: PubMed, EBSCO, Physiotherapy Evidence Database, ScienceDirect, The Cochrane Library, and SpringerLink databases.

\section{Selección de estudios}

Se incluyeron estudios: 1) con diseño de ensayo clínico controlado (ECC); 2) que incluyeran pacientes con dolor de cuello y hombro asociados a PGM; 3) que utilizaran acupuntura o PS como intervención, y 4) que tuvieran al menos una medida de reporte de resultados para la intensidad del dolor, ya sea uti- lizando escala análoga visual o la escala numérica. Se excluyeron estudios: 1) donde los PGM se definieran de acuerdo a los criterios de Simons y col1; 2) que incluyeran pacientes con dolor de cuello y hombro asociados a PGM latentes; 3) que comparasen entre sí diferentes tipos de PS; 4) que informasen datos y/o resultados.

\section{Extracción de datos}

Dos revisores independientes analizaron los artículos y calificaron la calidad metodológica. Se extrajeron los resultados de la intensidad del dolor en forma de datos de media y desvío estándar (DE). Se identificaron 20 ECC con 839 pacientes. Estos compararon PS con controles (punción falsa), PS con punción húmeda y PS con otros tratamientos, tanto a corto, mediano y largo plazo.

\section{Resultados principales}

Se resumen en la tabla 1.

Tabla 1: Cambio en la escala de dolor comparando punción seca con otras intervenciones

\begin{tabular}{|c|c|c|c|}
\hline & $\begin{array}{c}\text { Punción seca vs control } \\
\text { (punción falsa) DME* (IC 95\%); p }\end{array}$ & $\begin{array}{l}\text { Punción seca vs punción húmeda } \\
\text { DME (IC 95\%); p }\end{array}$ & $\begin{array}{l}\text { Punción seca vs otros tratamientos } \\
\text { DME (IC 95\%); p }\end{array}$ \\
\hline $\begin{array}{l}\text { A corto plazo } \\
\text { ( } 0 \text { a } 3 \text { días) }\end{array}$ & $-1,91(-3,1$ a $-0,73) ; p=0,002$ & $-0,01(-0,41$ a 0,4$) ; p=0.98$ & $0,33(-0,12$ a 0,78$) ; p=0,15$ \\
\hline $\begin{array}{l}\text { A mediano plazo } \\
\text { (9 a } 28 \text { días) }\end{array}$ & $-1,07(-1,87$ a $-0,27) ; p=0,009$ & $1,69(0,4$ a 2,98); $p=0,01$ & $0,62(0,02$ a 1,21$) ; p=0,04$ \\
\hline $\begin{array}{l}\text { A largo plazo } \\
\text { (2 a } 6 \text { meses) }\end{array}$ & $-1,15(-3,34$ a 1,04$) ; p=0,3$ & $0,33(-0,11$ a 0,78$) ; p=0,14$ & $0,58(-0,18$ a 1,34$) ; p=0,13$ \\
\hline
\end{tabular}

DME: diferencia de medias estandarizada

\section{Conclusiones}

La PS puede ser recomendada para aliviar el dolor de cuello y hombro asociados a los PGM en el corto y mediano plazo, pero se encontró que la punción húmeda es más eficaz que la pun- ción seca en el alivio del dolor de cuello y hombros asociados a los PGM en el mediano plazo.

Fuente de financiamiento/conflicto de interés de los autores: No referida

\section{Comentario}

Los puntos con sensibilidad a la presión y los puntos causantes de dolor en el cuerpo han sido el objetivo de diversas intervenciones terapéuticas a lo largo de los años. En la década del 40, la Dra. Janet Travell redescubrió los puntos gatillo (PG), y desarrolló el concepto de las inyecciones sobre los PG. En esa misma década, se planteó que la punción en sí misma podía ser responsable, al menos en parte, del efecto terapéutico. Sin embargo, recién en 1979 aparece el primer artículo sobre la $\mathrm{PS}^{2}$. Inicialmente, se preferían las infiltraciones por sobre la PS para el tratamiento del dolor miofascial y los PG. A mediados de la década del 80 , los fisioterapeutas se empezaron a interesar sobre esta práctica, generando que en 1984, en los Estados Unidos un primer comité estatal aprobase la PS como una práctica del ámbito de la fisioterapia ${ }^{3}$. En la actualidad, la PS es una práctica contemplada en muchos países. Distintas investigaciones han demostrado múltiples efectos de la PS, como modificación en el entorno químico de los PG activos, reducción o eliminación del ruido de la placa motora, y dismi- nución de la sensibilidad periférica y central ${ }^{3}$. Respecto a esta revisión, la PS mostró beneficios a corto y mediano plazo comparada con la punción falsa; sin embargo comparada con punción húmeda, esta mostró mejores resultados a mediano plazo. Vale destacar que en futuros estudios deberían incorporarse otras variables de resultados, clínicamente relevantes como movilidad articular, escalas funcionales y algometría.

\section{Conclusiones del comentador}

Aunque los mecanismos subyacentes a la PS no han sido clarificados en su totalidad, la PS sobre los PG ha ganado un lugar dentro de la ciencia del dolor. Cabe destacar que esta técnica no sustituye a otras técnicas de terapia manual, pudiendo considerarse un método más eficiente, rápido y habilitante para el ejercicio.

\section{Leonardo Intelangelo [ Universitario del Gran Rosario. leonardo.intelangelo@gmail.com) ]}

Intelangelo L. La punción seca sería efectiva en el tratamiento del dolor de cuello y hombro asociados a puntos gatillos miofasciales. Evid Act Pract Ambul. 2015;18(4):109. Oct-Dic. Comentado de: Liu L, y col. Effectiveness of Dry Needling for Myofascial Trigger Points Associated With Neck and Shoulder Pain: A Systematic Review and Meta-Analysis. Arch Phys Med Rehabil. 2015;96(5):944-955. PMID: 25576642.

\section{Referencias}

1. Simons DG y col. Travell and Simons' myofascial pain and dysfunction: the trigger point manual, volume 1: upper half of body. Baltimore: Williams \& Wilkins; 1999.

2. Dommerholt $\mathrm{J}$ y col. Punción seca de los puntos gatillo: Una estrategia clínica basada en la evidencia. Barcelona: Elsevier; 2013.

3. Dommerholt J. Dry needling - peripheral and central considerations. J Man Manipulative Ther. 2011 Nov;19(4):223-7. 